Revista Tecnologia e Sociedade, Curitiba, v. 11, n. 23, 2015

ISSN (versão online): 1984-3526

ISSN (versão impressa): 1809-0044

\title{
A inovação por subtração. Contribuição para a sociologia do distanciamento ${ }^{1}$
}

Innovation through withdrawal. Contribution to a sociology of detachment.

\author{
Frédéric Goulet ${ }^{2}$ \\ Dominique Vinck ${ }^{3}$
}

Artigo submetido em jan./2015 e aceito para publicação em abr./2015.

\section{RESUMO}

O artigo analisa o processo de inovação através dos mecanismos de dissociação e distanciamento, em complemento às associações documentadas pela sociologia da tradução. Para tanto, abordam-se as chamadas inovações por subtração, das quais uma das características é justamente a de serem baseadas na diminuição de uma prática, ou da subtração de um determinado artefato. Tendo como fundo de tela o caso da transição para técnicas de cultivo de plantio direto, são destacados quatro mecanismos principais constitutivos da dissociação da aração: a associação centrífuga; o aumento da visibilidade de entidades e associações; a perda de visibilidade de outras entidades e associações; e a associação de novas entidades. Esta análise contribui para refinar a compreensão dos processos de distanciamento no âmbito da maioria das inovações.

Palavras-chave: sociologia. Inovação. Actor-Network Theory. Redes sociotécnicas. Distanciamento

\begin{abstract}
To develop the understanding of innovation processes conceptualized in terms of association through the "sociology of translation" (cf. actor-network theory) studies, this article analyses innovation processes in terms of dissociation and detachment mechanisms, examining innovation through "withdrawal"; that is, innovation based on reducing or withdrawing use of a practice - "subtracting", "detaching" - a given artefact. Specifically, it focuses on the shift to farming techniques that have eliminated ploughing, bringing to light four major mechanisms constitutive of dissociation : centrifugal association ; making entities and associations visible ; making other entities and associations invisible; bringing together or " associating " new entities. The study helps refine our understanding of the detachment processes at work in innovation.
\end{abstract}

Key-words: sociology. Innovation. Actor-Network Theory. Sociotechnical networks. Detachment

\footnotetext{
${ }^{1}$ Esse artigo é uma tradução reduzida do seguinte artigo original, publicado em francês : Goulet F., Vinck D. (2012). "L'innovation par retrait. Contribution à une sociologie du détachement. ", Revue Française de Sociologie, vol. 53, n², p.195-224. Foi publicado também em inglês, e em espanhol: Goulet F., Vinck D. (2012). "Innovation through Withdrawal. Contribution to a Sociology of Detachment ", Revue Française de Sociologie ENGLISH, vol. 53, n², p.117-146. / Goulet F., Vinck D. (2013). «La innovación por sustracción. Contribución a una sociología del desapego». REDES, Revista de Estudios Sociales de la Ciencia, vol. 19, n³6, p. 13-49.

2 Doutor em sociologia. Pesquisador no CIRAD (Centre de Cooperation Internationale en Recherche Agronomique pour le Développement), no laboratório UMR Innovation e laboratório internacional Agriterris (Argentina). Trabalha sobre processos de inovação, produção e circulação de conhecimentos, e relações entre ciência e indústria no setor agrícola, na França e na Argentina. frederic.goulet@cirad.fr

${ }_{3}$ Professor da Universidade de Lausanne. Membro do Instituto de Ciências Sociais, ele dirige o Laboratório de culturas e humanidades digitais (LaDHUL). Sua pesquisa se concentra sobre a sociologia da ciência e da inovação. Atualmente investe no campo da engenharia das culturas e humanidades digitais. Suas publicações incluem: Engenhieros no Cotidiano. Etnografia da Atividade de Projeto e Inovação (Ed Fabrefactum, 2013; Ed americana, MIT Press, 2003), The Sociology of Scientific Work. The Fundamental Relationship between Science and Society (E.Elgar, 2010; Ed espanhol, Gedisa, Barcelona, 2015). Dominique.Vinck@unil.ch
} 
Revista Tecnologia e Sociedade, Curitiba, v. 11, n. 23, 2015

ISSN (versão online): 1984-3526

ISSN (versão impressa): 1809-0044

\section{INTRODUÇÃO}

Apesar de suas divergências, as diferentes abordagens sociológicas relativas à inovação - a corrente de pensamento difusionista (RYAN e GROSS, 1943; ROGERS, 1962), a história social da tecnologia (HUGHES, 1983), a sociologia construtivista da tecnologia (PINCH e BIJKER, 1984) ou a teoria do ator-rede (CALLON, 1986) - partem da mesma premissa, ou seja, de que a inovação é construída em torno da introdução de um novo elemento (artefato, serviço) e que o seu sucesso depende do número de adeptos e entidades que se articulam em torno do mesmo (AKRICH, CALLON e LATOUR, 1988). Este artigo pretende, contudo, lançar luz sobre as inovações que não estão organizadas em torno do "acréscimo", da adição, mas em torno da "subtração" de alguma coisa. Partimos da hipótese de que elas correspondem a um conjunto de fenômenos sociotécnicos, os quais devem ser examinados para elaborar uma nova problemática da inovação e contribuir para o estudo de processos de distanciamento.

\section{UMA NOVA PROBLEMÁTICA DA INOVAÇÃO}

Duas observações nos levam a definir uma problemática renovada do processo de inovação e contribuir para uma sociologia do distanciamento.

\section{PENSAR A PARTIR DO "MENOS" OU DO "SEM"}

A primeira observação é de ordem empírica: muitas inovações hoje são predominantemente estruturadas em torno da remoção de determinados componentes ou do seu uso mais moderado. De fato, a maioria das inovações referentes à introdução de alguma novidade inclui o corolário do desaparecimento e a subtração de uma prática ou de um objeto "substituído" por aquela novidade. No entanto, se, por exemplo, na inovação de um produto, houver a remoção de alguns elementos, esta subtração não é particularmente estruturante (SCHUMPETER, 1934). Portanto, se o desenvolvimento do milho híbrido ou da máquina fotográfica digital tem como base a substituição dos grãos tradicionais ou da prata, respectivamente, a inovação não é necessariamente definida sob este ângulo. Entretanto, nas inovações que estamos abordando, o elemento estruturante é 
Revista Tecnologia e Sociedade, Curitiba, v. 11, n. 23, 2015

ISSN (versão online): 1984-3526

ISSN (versão impressa): 1809-0044

precisamente e justamente a subtração de um dos componentes da rede sociotécnica, ainda que vários outros sejam adicionados, removidos ou transformados.

Estas "inovações por subtração" são frequentemente descritas por seus proponentes como uma resposta aos efeitos negativos da sociedade industrial, aos riscos ao meio ambiente e o bem-estar produzidos pelo progresso científico e técnico. Assim, a cidade livre de carros, a agricultura sem pesticidas; e os alimentos sem corantes ou conservantes constituem mitos mobilizadores (HATCHUEL, 1998) que estimulam os processos de inovação para um desenvolvimento "sustentável" e o bem-estar dos indivíduos. De maneira semelhante, em alguns casos, são entidades humanas que sofrem mudanças supressivas de alguma natureza, a exemplo dos intermediários das cadeias agroalimentares no âmbito do desenvolvimento de circuitos "curtos", de venda "direta", com a ambição de "aproximar" entidades que não estavam diretamente envolvidas, como produtores agrícolas e consumidores ${ }^{4}$. Assim, uma característica essencial destas inovações por subtração é que elas estão associadas a uma transição de uma retórica do "melhor" através do "menos" e do "sem", clamando por "encurtar", "reduzir", "diminuir" ou "apagar" a presença de certos elementos, e que são projetadas para distanciar os atores envolvidos destas.

\section{ESTUDAR AS DISSOCIAÇÕES E OS DISTANCIAMENTOS}

A segunda observação que nos leva a levantar esta questão da subtração é de natureza teórica. As inovações via subtração, ao invés de constituírem uma categoria nova de inovação ontologicamente diferente daquelas já identificadas ${ }^{5}$, representam nada mais que uma nova forma de questionar como os sociólogos têm tratado os processos de inovação. Ao tentar entender o processo pelo qual as inovações nascem, se transformam ou se tornam difusas, essas abordagens concentram seus esforços sobre os processos que acompanham a adição de algo e a criação de novos laços em torno desse algo. Consequentemente, investigações empíricas buscaram estudar e descrever a difusão, a adoção ou a adesão, a mobilização e o envolvimento de novas entidades. Vários autores se debruçaram

4 Dubuisson-Quellier e Le Velly (2008) mostram hibridizações que surgem no campo entre a figura do mercado longo com os seus intermediários e a figura do mercado da relação direta entre produtores e consumidores.

5 Inovações de produto vs inovação de processo (SCHUMPETER, 1934), mas também inovações organizacionais, inovações incrementais versus inovações disruptivas (CHRISTENSEN, 1997), inovações regulares vs inovações arquitetônicas (ABERNATHY e CLARK, 1985), etc. 
Revista Tecnologia e Sociedade, Curitiba, v. 11, n. 23, 2015

ISSN (versão online): 1984-3526

ISSN (versão impressa): 1809-0044

sobre o distanciamento: por exemplo, a noção de destruição criativa de Schumpeter, ou para Callon, a necessidade de desfazer as associações preexistentes para a introdução de inovação. Este último escreve que "para vincular-se a B, A deve cortar todos os laços que a massa invisível ou de fato presente, ativa ou passiva, das outras entidades C, D, E... tenta estabelecer com B" (1986, p.186) ou que "o sistema de incentivos encoraja as entidades a se aderirem, enquanto interrompe eventuais associações concorrentes e constrói um sistema de alianças." (Ibid. , p. 189). No entanto, é preciso reconhecer que os sociólogos da inovação e da tradução têm pouco estudado estes mecanismos de dissociação ou distanciamento ${ }^{6}$, focando mais em traduções vistas como construção de novas associações e conexões ${ }^{7}$ do que na quebra das relações preexistentes, embora, do ponto de vista dessa mesma sociologia, ambos os processos caminhem juntos.

As inovações baseadas na subtração constituem um convite para: (re)pensar a importância dessas dissociações e destes distanciamentos; e inserir-se no campo de pesquisas, contribuindo para uma "sociologia do distanciamento". Para isso, sugerimos a implementação de um princípio de simetria adicional no estudo das inovações, almejando o estudo das associações e das dissociações, das conexões e dos distanciamentos que se operam. Este princípio já foi enunciado pela sociologia da tradução, mas raramente posto em prática. $O$ caso das inovações por subtração nos confronta tão fortemente para a importância do trabalho de distanciamento que este já não pode mais ser ignorado. A hipótese que decorre desta posição seria a de que o que faz a força de uma inovação são, tanto a força e a quantidade de vínculos permanentemente quebrados, quanto a quantidade e a força dos laços que ligam as entidades a um projeto inovador.

Propomo-nos a confrontar esta hipótese de trabalho à transformação das práticas agrícolas. Especialmente na Europa, há esforços para orientar as práticas dos agricultores para redução do uso de agrotóxicos, adubos químicos ou outros insumos sintéticos considerados de risco para o meio ambiente e a saúde humana. Neste contexto, estão sendo desenvolvidas, desde o final da década de 1990 na França, práticas agrícolas que se caracterizam pelo fato de o solo não ser arado antes do uso (as chamadas técnicas de plantio direto ${ }^{8}$ ).

6 Para uma abordagem similar na sociologia dos mercados, ver Callon et al. (2002)

7 A noção de conexão ou ligação, desenvolvida por Callon (1999) define a construção de um universo de singularidade em torno de uma entidade.

${ }^{8}$ Veremos mais adiante que essas técnicas estão sujeitas a fortes controvérsias ambientais, porém 
Revista Tecnologia e Sociedade, Curitiba, v. 11, n. 23, 2015

ISSN (versão online): 1984-3526

ISSN (versão impressa): 1809-0044

\section{O CAMPO: DESENVOLVIMENTO DE TÉCNICAS DE PLANTIO DIRETO NA} FRANÇA

$\mathrm{Na}$ França, as técnicas de plantio direto (TPD) cresceram significativamente, chegando a compor um terço da superfície cultivada em cereais e oleaginosas (CHAPELLE-BARRY, 2008). Elas foram desenvolvidas, em sua maioria, em grandes fazendas por agricultores em busca de soluções técnicas para reduzir os seus custos de produção e o tempo de trabalho. A técnica de aração ${ }^{9}$, a qual os agrônomos consideram como essencial para a realização de certas funções agronômicas (controle e destruição mecânica de ervas daninhas, melhoria da estrutura do solo), na verdade, é uma das operações agrícolas mais custosas em tempo e dinheiro. As TPD, por sua vez, cobrem uma ampla variedade de práticas, normalmente agregadas em duas "famílias" (LABREUCHE et al., 2007): técnicas simplificadas de cultivo (TSC); e plantio direto (PD). As primeiras envolvem a substituição das técnicas de aração por operações superficiais, sem revirada do solo. A segunda consiste em não realizar qualquer tipo de trabalho no terreno, mesmo superficial, e apenas fazer um processo de plantio onde as sementes são colocadas diretamente no solo. A técnica de plantio direto (PD) foi desenvolvida na década de 1970 nos Estados Unidos e em seguida no Brasil, através de colaborações entre os agricultores, os agentes de estruturas estatais de pesquisa e desenvolvimento agrícola, e as empresas privadas de suprimentos agrícolas (COUGHENOUR, 2003; EKBOIR, 2003). O desafio era econômico, mas também ecológico: naqueles países, o uso intensivo do solo tinha levado ao surgimento de graves problemas de erosão. Para reforçar a proteção do solo, a manutenção de uma cobertura permanente foi incentivada. $\mathrm{Na}$ América, como na França, agricultores mantêm esta cobertura até hoje retendo resíduos da safra anterior (usando palha de trigo, por exemplo) ou através da implantação de plantas de cobertura. É por isso que o PD é muitas vezes citado por seus promotores com o termo de "agricultura de conservação" dos solos ${ }^{10}$.

vamos nos concentrar aqui na análise de processos de subtração/redução de trabalho.

9 Operação que consiste em trabalhar o solo, utilizando arado.

$10 \mathrm{Na}$ França, as organizações que promovem a TPD ou a agricultura de conservação, têm experimentado um crescimento significativo desde o início da década de 2000. Assim, a associação BASE (Bretanha, Agricultura, Solo e Meio ambiente) reunia 750 membros em 2011 (tinha seis na sua criação em 1999), em uma área geográfica cada vez mais extensa (16 departamentos, 40000 ha cultivados). 
Revista Tecnologia e Sociedade, Curitiba, v. 11, n. 23, 2015

ISSN (versão online): 1984-3526

ISSN (versão impressa): 1809-0044

\section{SUBSTITUIR FERRAMENTAS TÉCNICAS POR ELEMENTOS DA NATUREZA}

Mesmo que as motivações iniciais dos agricultores franceses fossem principalmente de natureza econômica e o estado de degradação dos solos não fosse comparável com o de seus colegas do continente americano, ainda assim, o conceito de agricultura de conservação surgiu no final de 1990, juntamente com as técnicas de plantio direto com coberturas vegetais. Este surgimento conjunto de novos registros práticos e discursivos está diretamente relacionado às viagens de estudo feitas na época por grupos de agricultores franceses aos Estados Unidos da América, ao Brasil e à Argentina, e às tentativas de adaptar o plantio direto na França. Uma viagem para o Brasil em 1998 teve um papel essencial neste processo. Agricultores, na busca incessante por inovações, foram ao encontro de um agrônomo do Centro de Cooperação Internacional em Pesquisa Agronômica para o Desenvolvimento (CIRAD, França), Lucien Seguy, naquele momento trabalhando na região central do Brasil com pesquisa agronômica local voltada para o desenvolvimento de sistemas de plantio direto. O guia de viagem foi um exmicrobiologista de solos do Instituto Nacional de Pesquisa Agronômica (INRA, França), Claude Bourguignon, fundador de um laboratório de análise independente dos solos, cuja atividade se baseia na conscientização dos agricultores franceses sobre importância dos solos e sua atividade biológica. Os dois profissionais se conhecem e compartilham uma visão comum sobre como devem ser as relações das Ciências Agrárias com a profissão de agricultor: a de uma Ciência a serviço dos agricultores, ajudando-os a inovar, e inspirando-se das inovações deles. Este modelo contrasta com a ideia de uma ciência fechada, distante do mundo agrícola e dos cidadãos. Séguy defende uma agronomia do campo, conduzida pelos e para os agricultores, com base em experimentos realizados entre eles e não em estações experimentais (GOULET, GROSSO, 2013). Bourguignon destaca sua trajetória pessoal, lembrando a sua saída espontânea do INRA em 1980, com o intuito de mostrar sua discordância com um modelo de desenvolvimento agrícola que considerava desfavorável aos agricultores e ao meio ambiente.

A ideia geralmente aceita no meio da pesquisa agrícola e defendida pelo microbiologista frente aos agricultores é simples: na ausência de aração e de qualquer tipo de preparo do solo, a biodiversidade e a atividade biológica do solo 
Revista Tecnologia e Sociedade, Curitiba, v. 11, n. 23, 2015

ISSN (versão online): 1984-3526

ISSN (versão impressa): 1809-0044

crescem e desempenham as funções do arado. As minhocas se multiplicam, aumentando a porosidade e a estrutura do solo. $O$ plantio direto também facilita o desenvolvimento de microrganismos, transformando os resíduos das coberturas vegetais em nutrientes, ou o desenvolvimento na superfície do solo de espécies predadoras naturais de certas pragas, como os besouros, predadores de lesmas. A supressão da aração é, portanto, baseada em um princípio simples: eliminar ou reduzir o uso de objetos técnicos, que serão substituídos "espontaneamente" em suas funções por entidades da natureza, e, assim, manter altos níveis de rendimento, preservando o ambiente.

\section{FERRAMENTAS TÉCNICAS FACILITADORAS DO PLANTIO DIRETO}

A ideia de manter a produtividade elevada é importante para melhor compreender e descrever os discursos e as práticas associadas ao PD. A retórica dos agentes destaca a necessidade de contar com os processos naturais, renunciando à aplicação de operações técnicas para arar o solo, mas sem deixar de lado a intervenção técnica. O plantio direto, por exemplo, só se tornou possível graças ao desenvolvimento, por parte das empresas privadas de suprimentos agrícolas, de duas técnicas principais: a semeadora de plantio direto para um plantio sem que a terra seja trabalhada e através de uma cobertura vegetal; herbicidas para suprir a supressão da aração, que destruía mecanicamente as ervas daninhas. A prática do plantio direto apoia-se, até hoje, na pulverização de herbicidas que têm como princípio ativo o glifosato ${ }^{11}$ para limpar o campo antes do plantio, e, se necessário, destruir a cobertura vegetal. Empresas agroquímicas e fabricantes de semeadoras são, assim na França, como em diversos países do continente americano (HALL, 1998), atores particularmente ativos na promoção e desenvolvimento do PD.

Se os defensores do PD argumentam em prol de um papel central para a natureza, a introdução de novos métodos técnicos continua a ser essencial para a sua valorização. Todavia, seus adeptos e proponentes enfatizam, sobretudo, a

11 O glifosato, que hoje faz parte do setor industrial público, foi concebido no início dos anos 1970 pela empresa Monsanto dos EUA. Comercializado sob o nome de Roundup, é o herbicida mais vendido no mundo. Suas vendas aumentaram fortemente nos anos 1990-2000 com o desenvolvimento, pela Monsanto, de culturas geneticamente modificadas para resistir à pulverização de glifosato (soja, algodão). Assim, o desenvolvimento do plantio direto em países como a Argentina esteve intimamente associado na década de 1990 com a "promoção" junto aos agricultores do pacote técnico "semeadoras + glifosato + soja GM" (Goulet e Hernández, 2011). 
Revista Tecnologia e Sociedade, Curitiba, v. 11, n. 23, 2015

ISSN (versão online): 1984-3526

ISSN (versão impressa): 1809-0044

questão da supressão de uma técnica (a aração), e seu instrumento de predileção (o arado), mais que o uso de novas semeadoras ou herbicidas. $O$ desenvolvimento do PD abre o caminho para a análise dos mecanismos de distanciamento com relação à técnica da aração com base na presença de novas entidades, técnicas ou da natureza, e de atores associados (produtores de semeadoras ou de herbicidas, "porta-vozes" dos microrganismos no solo). Estas mesmas entidades desempenham um papel-chave no mecanismo de distanciamento: colocadas entre as entidades a separar, elas facilitam a quebra de conexões existentes e o distanciamento. Trata-se então de investigar os processos pelos quais esta ruptura ocorre. Os mecanismos de dissociação não se limitam ao fim de relacionamento entre duas entidades, a saber, o fazendeiro e o arado. Outras entidades estão envolvidas, e nisso inclui-se agentes ou ex-agentes de instituições de pesquisa agrícola, empresas privadas de insumos agrícolas, assim como as semeadoras, as sementes, os solos, os herbicidas, as minhocas ou os microrganismos e muitos outros que a observação das redes sociotécnicas revelará.

\section{METODOLOGIA DE PESQUISA}

Para realizar a descrição e análise desses mecanismos, temos como ponto de partida o discurso produzido pelos "peritos" promotores do PD (técnicos do CIRAD, ex-microbiologista do INRA, representantes de empresas) durante conferências, seminários e encontros de formação para agricultores e os documentos correlatos (relatórios, livros). Também analisamos os conteúdos dos materiais informativos produzidos pelos coletivos de promoção e defesa do PD e pelas empresas de insumos agrícolas (publicidades, documentos comerciais e técnicos, sites). Por fim, usamos também como material de apoio cerca de trinta entrevistas individuais semiestruturadas realizadas na França com os seguintes interessados: peritos e consultores privados, agrônomos e cientistas do solo de instituições de pesquisa agrícola, técnicos e representantes comerciais de empresas de insumos agrícolas, e agricultores. Junto a estes, também realizamos em duas regiões francesas com contrastantes condições de solo e climáticas, observações de natureza etnográfica sobre o trabalho agrícola (o plantio, em particular), para entender as formas pelas quais as práticas e os discursos sobre essas práticas são recompostos em torno da supressão da aração e do arado. 
Revista Tecnologia e Sociedade, Curitiba, v. 11, n. 23, 2015

ISSN (versão online): 1984-3526

ISSN (versão impressa): 1809-0044

\section{MECANISMOS E PROCESSOS DE INOVAÇÃO POR SUBTRAÇÃO}

Callon (1986), para explicar a construção de ligações (as chamadas traduções) entre entidades heterogêneas, definiu quatro processos: problematização, interessamento, envolvimento e mobilização de aliados por meio de porta-vozes. Ele lembra que a inovação, vista como a construção de redes sociotécnicas, consiste em estabelecer novas conexões, assim como desfazer antigas ligações. Mas a conceituação analítica que lhe é própria foca principalmente no surgimento de novas ligações. Este autor ressalta que a criação de uma nova tradução passa pelo distanciamento de uma entidade de suas ligações habituais para desviá-la, e fazê-la se interessar e relacionar com outras entidades. O mecanismo consiste em se colocar na trajetória de um elemento, seja para impedi-lo de se ligar como ele teria feito sem a interferência do inovador, seja para convencêlo da impossibilidade da conexão prevista, a não ser que aceite um desvio pelo inovador. Mas, se os sociólogos da inovação documentam o estabelecimento de novas associações, eles apenas evocam o fato das problematizações (CALLON, 1986) ou estratégias retóricas (SUDDABY e GREENWOOD, 2005) retirando, assim, a legitimidade das instituições anteriores e desfazendo as associações prévias.

No caso em discussão, o laço que une a aração ao agricultor é sólido; a aração é uma prática profundamente enraizada nos padrões profissionais de agricultores franceses e de muitas partes do mundo (BRUNHES DELAMARRE e HAUDRICOURT, 1955 apud 1986). Por isso, é legítimo falar da aração como de uma instituição cujo conjunto de normas estabilizadas, de valores e de significados é, ao mesmo tempo, externalizado, indo além dos indivíduos, e internalizado por eles próprios (BERGER e LUCKMANN, 1967), de uma imposição de crenças e convenções, apoiadas em parte por marcos legais e procedimentos operacionais padronizados (MARCH e OLSEN, 1989). A aração enquanto instituição pode ser interpretada como uma relação de fidelidade a um conjunto de práticas, formas de pensar e crenças. A dissolução do vínculo que liga os agricultores à aração não é necessariamente óbvia. Trata-se de um desafio ao estabelecido (LOURAU, 1970) e de uma dinâmica da desinstitucionalização (MAGUIRE e HARDY, 2009).

Vamos demonstrar que quatro tipos de mecanismos estão envolvidos na separação entre os agricultores, a aração e o arado: a associação centrífuga, o 
Revista Tecnologia e Sociedade, Curitiba, v. 11, n. 23, 2015

ISSN (versão online): 1984-3526

ISSN (versão impressa): 1809-0044

reforço dos laços já existentes, a combinação de novos elementos e a colocação em invisibilidade de determinadas associações.

\section{A ASSOCIAÇÃO CENTRÍFUGA E O PONTO DE PASSAGEM A EVITAR}

Paradoxalmente, o primeiro mecanismo de distanciamento e de dissociação envolve a construção de novas associações entre as entidades descartadas (a aração e o arado) e outras entidades às quais o agricultor não está ligado ou não quer (mais) ser vinculado. Os promotores do PD representam negativamente a aração, associando-a com ameaças, perigos, objetos ou registros simbólicos desvalorizados e desvalorizantes para os agricultores. Seu trabalho é problematizar a prática da aração, colocando-a na intersecção de diferentes perigos e mostrando que a sua eliminação permitiria evitar esses perigos.

Inicialmente, os peritos, técnicos ou empresas se esforçam para associar a aração a uma ameaça econômica para os agricultores franceses. Com o apoio de quadros e cifras comparativas, eles afirmam que a sua subtração Ihes permitiria a manutenção nos mercados internacionais cada vez mais competitivos, embora o futuro dos subsídios públicos pagos no âmbito da política agrícola comum fosse incerto. Arar é muito caro, tornando-se uma desvantagem para os agricultores franceses frente ao crescimento de "campeões" do plantio direto nos mercados agrícolas, o Brasil e a Argentina, que não recebem nenhum subsídio público. Seria necessário espelhar-se nesses agricultores ao mesmo tempo precursores e concorrentes: "Eles têm sistemas muito menos onerosos que os seus [...] vocês deveriam estar aptos a fazer planos com 35L de combustível [...] e é possível" (Microbiologista dos solos).

Além do declínio econômico, os promotores do PD associam a lavra ao risco ecológico cujas manifestações já se fazem sentir. Com o suporte de slides, mostrando a erosão e os sulcos do solo, apoiados por números que refletem o alcance da catástrofe anunciada, os especialistas denunciam os males da aração sobre os solos ${ }^{12}$. Um deles faz a seguinte afirmação numa conferência:

Há uma dimensão ecológica, não só no contexto francês, eu diria que a nível mundial. [...] A erosão do solo torna-se um problema muito sério. Em

12 Esta dinâmica de subtração é comparável ao que promovem nas políticas públicas de saúde para incentivar a não fumar: colocar em embalagens de tabaco, fotos de órgãos doentes para mostrar os perigos a que se expõe o consumidor através do uso do objeto a ser "removido". 
Revista Tecnologia e Sociedade, Curitiba, v. 11, n. 23, 2015

ISSN (versão online): 1984-3526

ISSN (versão impressa): 1809-0044

6.000 anos de agricultura, criamos dois bilhões de hectares de deserto, dos quais um bilhão somente no século XX. [...] Todos os anos, há dez milhões de hectares que desaparecem para a agricultura. A erosão devida à intensificação da agricultura cresce a uma média de cerca de uma tonelada por hectare por ano. Todos os anos, vocês perdem mais uma tonelada.

Os especialistas também abordam os registros identitários e as frustrações sentidas pelos agricultores em termos de imagem, enfatizando essa dimensão ecológica, associando a aração ao espectro do agricultor poluidor, rejeitado pela sociedade francesa na década de 1990, após os escândalos de poluição agrícola, como no caso dos nitratos na água. Estes escândalos e sua subsequente midiatização têm afetado significativamente as identidades profissionais dos agricultores (LEMERY, 2003). A imposição de padrões ambientais e o reconhecimento público do princípio da multifuncionalidade foram percebidos como uma desvalorização social (LAURENT e RÉMY, 2004). Portanto, frente aos representantes de uma classe de profissionais afetada por essas crises - os produtores de grãos -, os especialistas suscitam o abandono do arado como uma porta de saída dessa fase ruim. Trata-se de tornar o ato de arar "indesejável" e o plantio direto desejável, destacando os benefícios simbólicos que os agricultores vão colher. Em uma conferência, um especialista aponta: "Vocês irão poluir muito menos e, assim, os consumidores ficarão muito felizes com esta mudança de práticas agrícolas".

As pessoas contrárias à aração também procuram associá-la a um perigo reacionário, à imagem de um mundo rural e agrícola marcado pelo imobilismo e o confinamento na tradição, impedindo a inovação. Fazendo do arado um símbolo da agricultura conservadora, eles apresentam o PD como a agricultura do futuro, já praticada no Brasil. O microbiologista dos solos aponta em uma conferência:

\begin{abstract}
A partir do momento em que países a desenvolvem, você não pode ficar apenas assistindo essa revolução verde, você não pode ficar no seu canto e continuar com uma agricultura arcaica, enquanto há pessoas que já têm cerca de 25 anos de evolução sobre você [...] as técnicas que descrevo já são praticadas sobre dezesseis milhões de hectares em todo o mundo.
\end{abstract}

Os promotores do PD ainda estendem a lista de entidades negativamente associadas à aração citando órgãos de pesquisa conservadores que contribuíram muito pouco para o desenvolvimento do PD na França. Os defensores do plantio direto acabam por associar a aração a uma estrutura de pesquisa e desenvolvimento presa à tradição, desligada das necessidades reais dos agricultores inovadores, trancada nos laboratórios ou outras estações experimentais e, portanto, cortada da 
Revista Tecnologia e Sociedade, Curitiba, v. 11, n. 23, 2015

ISSN (versão online): 1984-3526

ISSN (versão impressa): 1809-0044

experiência de campo. Em seu site, a Fundação Nacional por uma Agricultura de Conservação de Solos (FNACS) afirma ter: "Nascido em resposta às questões colocadas por um punhado de agricultores insatisfeitos com as respostas prontas das "agências oficiais", ITCF ${ }^{13}$, a Câmara da Agricultura, mas, sobretudo com a ignorância dessas organizações sobre o funcionamento in situ dos solos agrícolas."

É, portanto, todo um sistema tecnocientífico falho aos seus olhos que os proponentes do PD associam à aração. O ex-técnico do INRA ironiza e se coloca entre os agricultores e as instituições de pesquisa agrícola: "Eu sou microbiologista dos solos. Eu tenho uma formação um pouco especial, uma vez que eu estudei Agronomia em Paris, tendo feito na época do meu terceiro ano especialização em "microbiologia dos solos". É uma especialidade que foi extinta em 1986. Por isso, é tranquilo, eu não tenho concorrentes que apareçam no mercado há quatorze anos."

Ele liga o INRA às terras degradadas, ao imobilismo e à conspiração, colocando-se do lado dos interesses dos agricultores e dos solos. Assim, em um documentário lançado em $2005^{14}$, o microbiologista do solo diz:

Saímos do INRA, tornamo-nos autônomos. Porque quando a gente começou a mostrar que os solos estavam morrendo biologicamente, nos pediram para ficar quietos. Saímos do Instituto e seguimos nosso caminho, porque considerávamos que nosso dever de cientistas ainda era de alertar o mundo agrícola que o caminho escolhido não era bom. [...] Só pode haver agricultura sustentável se a terra estiver viva.

Finalmente, há também o imobilismo de revendedores de equipamentos agrícolas que os fomentadores do plantio direto associam à aração, pois, segundo estes, aqueles são resistentes ao $\mathrm{PD}$, pois geraria uma queda de vendas de maquinaria agrícola, de ferramentas ou tratores. A aração, e mais amplamente as ferramentas agrícolas, estão associados aos interesses mercantis da indústria da maquinaria agrícola, o que prejudicaria a capacidade de inovação dos agricultores, os deixando mais pobres.

Assim, o trabalho de separação passa pela agregação de uma multidão de aliados em torno da entidade a ser removida, a fim de torná-la insuportável. Os defensores do PD, combinando a aração a todas as ameaças que pesam sobre os agricultores e sobre a sociedade, os elegem como um ponto de passagem a ser evitado (PPE). Estas associações centrífugas ligam o PPE às entidades localizadas na periferia da rede, pois as mesmas são carregadas negativamente, deixando vago 
Revista Tecnologia e Sociedade, Curitiba, v. 11, n. 23, 2015

ISSN (versão online): 1984-3526

ISSN (versão impressa): 1809-0044

o centro desta, e fazendo aquele perder um papel outrora estruturante. Os especialistas realizam, ao longo dessa etapa, um reenquadramento, uma retradução para estimular o distanciamento: trata-se de mostrar aos agricultores que o que eles mais prezam não é o ato de arar, mas sim a produtividade, a competitividade e uma boa imagem, assim como uma boa gestão da natureza e dos solos. O PPE não é, portanto, uma definição oca do ponto de passagem obrigatório (PPO) proposto por Callon. O PPO foi estruturalmente definido como um nó de articulação entre várias redes separadas. Ao contrário, o ponto de passagem a ser evitado realça principalmente a existência de outras passagens possíveis. Neste caso, o PPE é o nó estruturante de uma rede sociotécnica em uma posição centralizada, que é levado a desaparecer, e cuja peculiaridade é que, em nenhum caso, outras entidades devem ser ligadas a ele.

\section{REFORÇO DAS RELAÇÕES, COM AUMENTO DA VISIBILIDADE DE ENTIDADES PREEXISTENTES}

O segundo mecanismo em ação no processo de distanciamento é aquele que consiste em tornar visíveis as entidades até então silenciosas ou invisíveis, para reforçar os laços que os associam aos atores. Há dois tipos de elementos que ganham visibilidade: os solos e outros seres vivos que os habitam e cuja atividade está relacionada com as funções desempenhadas até agora pelo arado ${ }^{15}$; e o conhecimento dos agricultores, essencial para lidar com os imprevistos práticos induzidos pelo desapego à aração. Este reforço das associações se dá através da retórica e de práticas demonstrativas de fenômenos agronômicos, tais como o impacto da remoção sobre a proliferação das minhocas.

\section{FOMENTANDO A VISIBILIDADE DOS SOLOS E DA SUA ATIVIDADE BIOLÓGICA}

Os especialistas, os agricultores pioneiros do PD e os agentes de empresas privadas enfatizam a importância dos solos e da sua atividade biológica para o sucesso do plantio direto. Eles, assim, promovem a terra do seu papel de simples "apoio" ao papel de componente de destaque de uma agricultura produtiva que respeita o meio ambiente. Em suas conferências ou seminários de formação, eles

15 Thiébaut (1994) destaca que o solo é, ao contrário da água ou do ar, um elemento pouco considerado pelas políticas ambientais. 
Revista Tecnologia e Sociedade, Curitiba, v. 11, n. 23, 2015

ISSN (versão online): 1984-3526

ISSN (versão impressa): 1809-0044

são os porta-vozes dessas entidades, mobilizando números e gráficos, mostrando, por exemplo, o aumento do número de minhocas em solos não arados, ou fotografias de micro-organismos projetadas na tela. Eles explicam o papel desses seres na aeração do solo, na degradação da matéria orgânica, e sugerem aos agricultores o que vai acontecer em seus campos se pararem de arar. Assim, o microbiologista do solo explica:

Isso vai novamente permitir que a fauna acima do solo se reorganize [...] vocês vão forçar os animais a reconstruir as suas galerias em cima e vocês vão ver que assim o seu nivelamento vai desaparecer, a água voltará a fluir em seu campo. Vocês permitirão a volta da porosidade aos seus solos, e você vão ver de novo como as raízes de seu trigo serão capazes de descer mais rapidamente nos solos.

Eles enfatizam números, referindo-se à natureza "onipotente", para sensibilizar e conscientizar os agricultores da riqueza, até então impensada, daqueles solos sobre os quais eles pisam diariamente: "Você sabia que em um grama de solo, há 800 metros a $1 \mathrm{~km}$ de micélio ${ }^{16}$ ?"

\footnotetext{
"Os solos contêm $80 \%$ da biomassa viva na terra; as minhocas sozinhas são mais pesadas que todos os outros animais reunidos; com um bom solo, em bom estado, você tem duas toneladas de micróbios por hectare; os micróbios têm uma atividade bioquímica 350 vezes maior do que a nossa".
}

Eles mostram o que era invisível, por ser muito pequeno ou subterrâneo. Eles incluem sistematicamente nos seminários de formação, a observação in situ de poços de solo, trincheiras cavadas nos lotes para observar as camadas mais profundas do solo. As minhocas, suas galerias e as raízes das plantas que descompactam o solo, até agora insuspeitas, são, então, reveladas aos olhos dos novatos. Uma bateria de ferramentas é mobilizada para esta prática de observação: enxadas, que permitem cavar buracos, e facas usadas no cinto para limpar as raízes ou abrir os torrões fazem parte do equipamento dos especialistas. A confrontação dos agricultores a estes aspectos do solo pode ser um momento de bifurcação no distanciamento da aração, como uma agricultora menciona: "Para mim, aquele momento mudou minha compreensão. Era óbvio [...] Eu não podia ver isso antes. Ele me dizia "tuas plantas, elas trabalham o solo no seu lugar...". [ ...] É como acreditar em Deus, enquanto eu não o ver ..."

Se até agora, arar era um ponto de passagem obrigatório (PPO), os

16 Parte vegetativa dos fungos do solo, capazes de facilitar a degradação da matéria orgânica ou aumentar a eficiência da absorção de água e nutrientes pelas plantas. 
Revista Tecnologia e Sociedade, Curitiba, v. 11, n. 23, 2015

ISSN (versão online): 1984-3526

ISSN (versão impressa): 1809-0044

promotores do PD mostram, portanto, que em última análise, trata-se apenas de um entre tantos, do qual os agricultores podem prescindir. Por meio dessas dissociações e desses estímulos à visibilidade, eles redesenham o mapa de arranjos sociotécnicos: eles buscam fazer com que entidades anteriormente discretas (minhocas) ocupem uma posição estrutural equivalente (WHITE, 1992) à aração, ou seja, firmemente ligadas ao sucesso das colheitas. Mas há consenso entre os especialistas: estes novos aliados só serão eficazes se não houver nenhum retorno ao arado, se ligações desligadas não se reatarem. Eles enfatizam que qualquer retorno à aração, ainda que pontual, teria o efeito de causar a perda dos ganhos obtidos em termos de atividade biológica, fazendo com que os agricultores e suas terras recomecem do zero. Entre estes dois cruzamentos, aração ou minhocas, é preciso escolher, porque os dois não podem coexistir.

\section{FOMENTANDO A VISIBILIDADE DO CONHECIMENTO DOS AGRICULTORES}

Os defensores e adeptos do PD enfatizam que a natureza não age sozinha: o agricultor tem que estar lá para gerenciar, compreender e melhor controlá-la. O plantio direto só se torna possível quando o agricultor desenvolve habilidades que os proponentes do plantio direto procuram tornar visíveis. Eles se distanciam formalmente das instituições de pesquisa e desenvolvimento consideradas imobilistas, refratárias à inovação, e reivindicam uma ruptura para com o modelo de inovação que reduz o agricultor a um papel passivo de "aceitador". Pelo contrário, eles colocam o agricultor no primeiro ranking dos agentes inovadores e detentores do conhecimento: "Pela primeira vez na história da agricultura, os agricultores estão à frente dos agrônomos, e é desta inovação que vem da base que vai sair a agricultura de amanhã". (BOURGUIGNON, 2002, p. 9).

Assim, os promotores e profissionais do PD criticam o modelo onde os agricultores são nada mais que implementadores, "sistemas de apertar botões" e "orientações" prescritas por conselheiros. $O$ abandono da aração reveste para eles uma dimensão política ${ }^{17}$ : constitui a "retomada do poder pelo agricultor", que "tornase seu próprio mestre, tomando para si o papel de tomador de decisão". Eles destacam a sua capacidade de inovar e produzir conhecimentos já existentes, porém

17 Sobre a dimensão política da inovação, os agricultores com esta afirmação identitária, as empresas agroindustriais com a instrumentalização do caráter ambiental do plantio direto, ver Goulet (2010). 
Revista Tecnologia e Sociedade, Curitiba, v. 11, n. 23, 2015

ISSN (versão online): 1984-3526

ISSN (versão impressa): 1809-0044

não reconhecidos. Para o presidente da associação Bretanha, Agricultura, Solo e Meio Ambiente (BASE): "A inovação vem dos agricultores. Ela sempre veio dos agricultores, mas não sabíamos disso antes".

O aumento da visibilidade das entidades já preexistentes, mas discretas, é essencial nos mecanismos de distanciamento. A supressão da aração, o seu desaparecimento da rede sociotécnica, deixa o campo aberto a entidades agora visíveis e às suas respectivas ligações com os agentes. O distanciamento passa pela etapa de identificação de novos pontos alternativos de passagem ou de um novo ponto de passagem obrigatório. Em troca, essas entidades que ganharam visibilidade perenizam a dissociação do arado e impedem o seu retorno. Mas também permanecem mecanismos de associação, com exceção das associações centrífugas; a supressão de um artefato (o arado) é acompanhada pela introdução de novos artefatos (semeadoras, herbicidas). Vamos examinar as maneiras em que coexistem introdução e supressão, dissociação e associação, distanciamento e novas conexões.

\section{A AGREGAÇÃO DE NOVAS ENTIDADES}

A introdução de semeadoras e herbicidas tornou possível a dissociação entre o arado e os agricultores sem comprometer a safra. Sem essas novas entidades, não haveria plantio direto: o campo seria invadido por ervas daninhas, e o plantio não poderia ser feito por causa dessa cobertura vegetal. As empresas associadas a estas entidades foram particularmente ativas para fazer de seus produtos objetos essenciais, especialmente visíveis através de suas alianças com especialistas promotores do PD. Assim, a fabricante brasileira de semeadoras diretas, Semeato, foi introduzida no mercado francês, através do desenvolvimento de uma relação especial com Séguy, agrônomo do CIRAD no Brasil. Enquanto este último considera a marca como a "Mercedes das semeadoras diretas", ele se torna também um personagem chave das viagens que a empresa organiza no Brasil para seus clientes franceses. Da mesma forma, ela o convida, assim como outras empresas da França, a dar palestras para seus clientes.

Por meio do marketing e da publicidade, as empresas tentam chamar a atenção dos agricultores, misturando em seus slogans diferentes registros retóricos. Assim, um fabricante argentino de semeadoras convoca os agricultores franceses usando um repertório econômico e ecológico: "façam economias e evitem o 
Revista Tecnologia e Sociedade, Curitiba, v. 11, n. 23, 2015

ISSN (versão online): 1984-3526

ISSN (versão impressa): 1809-0044

aquecimento global"18. Fabricantes de semeadoras ou pulverizadores enfatizam a produtividade e o desempenho de seus produtos, procurando fidelizar a clientela das grandes fazendas de grãos. Uma fabricante alemã orgulha-se de ter plantado "98 hectares em 24 horas, com uma semeadora de 3 metros", enquanto uma empresa de pulverizadores destaca o "primeiro recorde mundial de pulverização terrestre: 102,57 hectares em 1 h 14 min 14 segundos." Finalmente, a maioria dessas empresas também assegura a qualidade da consultoria que elas são capazes de fornecer aos agricultores, no serviço de pós-venda expandido que vai compensar a falta de experiência dos atores tradicionais no desenvolvimento agrícola. A Monsanto insiste, por exemplo, no anúncio para o Roundup, publicado na primeira edição da revista TCS, em 1999, sobre a assistência e assessoria técnica que ela se propõe a fornecer aos agricultores.

E os promotores do PD, entre os quais as empresas de suprimentos agrícolas, se esforçam para construir e fortalecer as associações entre os profissionais e uma variedade de artefatos técnicos. Eles desenvolvem palestras, serviços associados a objetos, para incluí-los no uso dos profissionais e nas redes sociotécnicas de plantio direto. Eles podem não ser o centro da inovação, mas são os facilitadores do desapego à aração. Estas operações de promoções de novos objetos consistem em tornar seu uso uma consequência inevitável da supressão ocorrida, ao lado da fauna dos solos ou do conhecimento de agricultores que ganharam visibilidade.

\section{FOMENTANDO A INVISIBILIDADE DE CERTAS ENTIDADES E CONEXÕES}

Todos os ingredientes parecem estar presentes para que o distanciamento da aração seja eficaz: os agentes estão, a priori, convencidos de que continuar a arar vai contra os seus interesses, mas também que as condições estão reunidas para que os sistemas de cultivo de plantio direto "funcionem". Contudo, o estudo de canais interpessoais e dos discursos revela que um quarto mecanismo está envolvido neste processo de desapego. Trata-se de tornar invisíveis entidades e relações indesejáveis, tais como entre herbicidas e a poluição, ou entre empresas e a exploração comercial dos agricultores. Isto ajuda a manter a coerência e o sentido

$18 \mathrm{Em}$ referência à redução do consumo de combustível e, consequentemente, das emissões de gases de efeito estufa, assim como à retenção de carbono em solos que permitem o plantio direto associada a uma cobertura permanente do solo vivo. 
Revista Tecnologia e Sociedade, Curitiba, v. 11, n. 23, 2015

ISSN (versão online): 1984-3526

ISSN (versão impressa): 1809-0044

que os atores querem construir em torno dessa supressão. Alguns elementos, tais como máquinas, herbicidas e empresas, de fato fazem parte de categorias ligadas à associação centrífuga. Tornava-se então importante se distanciar da mesma, de se afastar dos técnicos e vendedores por conta dos danos que eles causariam nos ecossistemas e no mundo camponês. A aração, o arado e os "sucateiros", como são chamados aqueles que não aram, foram alçados a porta-vozes dessas categorias a evitar. Como, então, juntar-se a essas entidades, sem que haja contradição, mantendo as dissociações estabelecidas? Isso requer que essas entidades e associações fiquem invisíveis para os agentes da TPD. Os agricultores, em primeiro lugar, minimizam a sua importância na sua prática e nos fatores de sucesso da TPD. A semeadora é, assim, concebida como um simples componente da ação, não desempenhando nenhum papel importante. Como disse um agricultor: "O importante não é a máquina ou a marca. Seja ela vermelha, azul ou verde, o que realmente importa é o que fazemos dela."

O que importa é a habilidade do agricultor, sua criatividade. A semeadora, enquanto componente de um roteiro que vai alinhar as práticas dos usuários com um conhecimento oriundo de fora, pode dificultar a visibilidade e o desenvolvimento de conhecimentos do agricultor. Quanto aos herbicidas, os agricultores realçam seus esforços para otimizar o uso dos mesmos (pulverização de precisão, escolha refinada das condições de aplicação), afirmando que não houve aumento do uso destes. Isso é para manter-se longe dos riscos que esses objetos podem levar ao meio ambiente, à saúde ou à imagem dos agricultores. Possíveis PPE, esses objetos, entretanto imprescindíveis para a ação, são invisíveis para o benefício de outros recursos naturais, cognitivos, mais em sintonia com a forma como os jogadores querem definir o plantio direto e sua profissão.

As empresas que projetam e produzem esses objetos contribuem para este cenário de invisibilidade, fazendo-se discretas aos olhos dos agricultores e do público em geral. Elas pertencem a uma categoria de agentes previamente associados ao imobilismo, que impedia os agricultores de avançar e inovar. Porém elas obtêm sucesso, como todos os instrumentos técnicos que elas projetam, ao desempenhar um papel fundamental na dinâmica do distanciamento. Como elas podem ser ao mesmo tempo denunciadas e próximas dos agentes que defendem a supressão da aração? A estratégia da empresa brasileira Semeato é esclarecedora para analisar este fenômeno. Posicionada na faixa mais bem sucedida da TPD, a da 
Revista Tecnologia e Sociedade, Curitiba, v. 11, n. 23, 2015

ISSN (versão online): 1984-3526

ISSN (versão impressa): 1809-0044

semeadora direta, ela destaca o impacto mínimo e localizado do seu produto no solo do plantio, fazendo com que haja apenas uma pequena perturbação, tornando-se quase invisível perto dos vestígios que ela deixa no chão. Ela também atribui uma importância central à experiência do cliente, promovendo uma relação com o sistema comunitário de vida, durante reuniões, viagens, e trocas horizontais entre pares. Esta iniciativa é parte de um suporte essencial para os profissionais: a empresa fornece os recursos cognitivos, facilita sua circulação, a fim de definir novos apoios para a ação. Ela escolhe um modo específico de penetração no mercado de semeadoras sem ser representada por concessionárias, mas por agricultores adeptos do plantio direto e usuários assíduos dos produtos da marca. Entre os agricultores-vendedores e clientes-pares, a relação comercial é diluída em uma relação de cooperação e consultoria onde o intangível e o ideal têm precedência sobre o tangível e o mercantil (GOULET, 2011). A empresa, por meio de seus agricultores-vendedores parece empenhada ao lado dos agricultores em uma luta comum contra os mesmos perigos e pelas mesmas conquistas.

O modo de ação das empresas químicas também tem como base esse princípio. Trata-se em primeiro lugar de minimizar o impacto dos seus herbicidas no solo, envolvendo-se na elaboração dos discursos e dos conhecimentos que garantem a sua inocuidade. Assim, com sucessos às vezes relativos ${ }^{19}$, a empresa norte-americana Monsanto tenta demonstrar o caráter inócuo do glifosato no solo, no meio ambiente e na saúde humana. Ela também procura ser bastante discreta, apoiando financeira e logisticamente organizações que promovem o PD e ajudando a construir em torno delas a imagem de um movimento focado e dirigido por agricultores inovadores. Assim, um engenheiro ambiental da empresa, que tem como missão apoiar o desenvolvimento do PD na França, foi até 2011 secretário da associação regional BASE, da associação nacional APAD e da organização europeia European Conservation Agriculture Federation (ECAF).

Uma de suas funções é garantir a promoção dessa inovação em muitos eventos públicos, políticos e científicos, sempre sob a identidade de um representante dessas organizações e não como um empregado da firma. Junto ao pesquisador, ele insiste também em enfatizar seu compromisso pessoal e a

19 Há controvérsias sobre a inocuidade do glifosato e dos seus derivados sobre a qualidade das águas subterrâneas e a saúde humana. Na França, a Corte de Cassação de Lyon condenou em outubro de 2009, por propaganda enganosa a empresa americana que afirmou que o Roundup é "biodegradável" e "deixa o solo limpo". 
Revista Tecnologia e Sociedade, Curitiba, v. 11, n. 23, 2015

ISSN (versão online): 1984-3526

ISSN (versão impressa): 1809-0044

abordagem "intelectual" com os agricultores. Por meio desta estratégia de tornar invisíveis os seus herbicidas e a si mesma, a empresa construiu em torno do PD a imagem de uma inovação ecológica que veio de baixo para cima. Através deste trabalho, as empresas de fornecimento de produtos agrícolas criam um discurso e uma estratégia onde se definem como atores secundários ao lado de outros atores do processo de inovação ${ }^{20}$. De fato, a rede associa: os agricultores que não aram a terra, não retrógrados e não poluidores; os peritos e pesquisadores que não estão isolados em seus laboratórios ou estações de experimentação; e os empregados de firmas não poluidoras e não mercantis; assim como os solos que não estão danificados. Todos estes elementos estão mobilizados em torno do plantio direto.

\section{CONCLUSÃO}

A contribuição desta pesquisa se encontra na análise da elaboração dos mecanismos de dissociação no cerne dos processos de inovação e sua contribuição para a sociologia do distanciamento. Foi confirmada a hipótese de que a força de uma inovação repousa tanto sobre a força e a quantidade das conexões quebradas quanto sobre aos vínculos construídos pelos agentes intervenientes. Ela nos convida a postular sobre a importância de um terceiro princípio de simetria que vai permitir apoiar a análise sociotécnica das inovações: uma atenção igual aos sucessos e aos fracassos, humanos e não humanos, mas também às associações e dissociações. $O$ conceito de inovação por meio da subtração e o exame das suas dinâmicas enriquecem a análise sociotécnica e a sociologia da tradução, enfatizando a importância dos mecanismos de dissociação e de distanciamento, em relação aos conceitos mais famosos de associação, interessamento, envolvimento e mobilização. Nós mostramos que o distanciamento é, em primeiro lugar, o resultado de um trabalho de interposição, realizado pelos empreendedores da inovação no contexto das associações existentes entre as entidades a serem removidas e os atores. Através de um trabalho de associação centrífuga e de reconversão dos interesses fundamentais desses atores, essas entidades se tornam indesejáveis e se transformam em pontos de passagem a serem evitados (passo 1). Elas estruturam o

20 Vários autores (HALL, 1998; GOULET, 2010) destacaram a estratégia de comunicação implantada por empresas agroquímicas em torno do sistema de plantio direto para tornar mais verde sua imagem, ao mesmo tempo em que elas sofriam de uma percepção negativa por parte do público sobre o impacto de suas atividades no meio ambiente. 
Revista Tecnologia e Sociedade, Curitiba, v. 11, n. 23, 2015

ISSN (versão online): 1984-3526

ISSN (versão impressa): 1809-0044

processo de forma original na medida em que o novo layout é construído em torno de seu distanciamento, da sua subtração desejada e da sua ausência.

Esta separação é reforçada e perpetuada pela construção ou fortalecimento de associações. Assim, o aumento da visibilidade das entidades e suas relações com as partes interessadas (passo 2), mas também sua associação com novas entidades (passo 3) constroem pontos alternativos de passagem às entidades removidas. Estas associações e dissociações tornam-se mais ou menos visíveis: algumas associações são exibidas abertamente, enquanto outras são mantidas na discrição (passo 4). A identificação de tais mecanismos de (in)visibilidade mostra que todos os pontos não estão associados da mesma maneira em redes sociotécnicas. De acordo com os interesses, as partes interessadas apresentarão certas entidades ou associações, em vez de outras: deve ser considerado o significado atribuído pelos atores para a inovação e para a questão do distanciamento.

Sem contradizer os princípios da teoria do ator-rede, esta postura chama a atenção para as trajetórias dos atores, o coletivo em relação ao qual eles se identificam. Ela pede que se considere a inovação e o distanciamento, não só do ponto de vista dos inovadores, mas também da visão de todos os atores envolvidos no processo, das suas práticas, estratégias, e dos significados que eles expressam. Isso ajuda a mostrar que a remoção de um artefato estrutura o processo, pois os próprios interessados são o elemento central, de acordo com as problematizações operadas sucessivamente por estes e suas questões estratégicas ou identitárias.

Finalmente, esta pesquisa contribui para alimentar o distanciamento como problemática sociológica. Se esse distanciamento não é trazido à tona, a análise da proibição de práticas rotineiras e institucionalizadas terá contribuído para seu estudo (ver, por exemplo, Maguire e Hardy (2009) sobre a proibição do inseticida DDT). O processo de associação centrífuga faz um recorte desta desinstitucionalização, mas nós mostramos que a remoção não se resumia apenas a isso: o distanciamento implica também na construção de novas associações e no aumento de visibilidade para as alternativas de desvio do ponto de passagem a evitar. Esta dimensão teve destaque no trabalho que sociólogos e antropólogos têm conduzido sobre os rituais de luto com sucessivos atos de desprendimento dos mortos (CARADEC, 2001; HETHERINGTON, 2004) ou na luta contra a dependência de drogas por apego a substitutos (GOMART, 1999). 
Revista Tecnologia e Sociedade, Curitiba, v. 11, n. 23, 2015

ISSN (versão online): 1984-3526

ISSN (versão impressa): 1809-0044

Pela sua proximidade com as observações e análises produzidas a partir de áreas e temas de vários estudos, a pesquisa na qual este artigo se baseia sugere que sociologia da inovação pode contribuir para uma sociologia do distanciamento. Quanto aos slogans societais enfatizando a necessidade de se construir um desenvolvimento "sustentável", a perspectiva de uma análise aprofundada das condições de desapego abre o caminho para uma análise sociológica renovada das inovações.

\section{REFERÊNCIAS}

ABERNATHY W. J., CLARK K. B., 1985. Innovation: mapping the winds of creative destruction, Research policy, 14, 1, pp. 3-22.

AKRICH M., CALLON M., LATOUR B., 1988. À quoi tient le succès des innovations? 1: L'art de l'intéressement, Annales des Mines, 11, pp. 4-17.

BERGER P., LUCKMANN T., 1967. The Social Construction of Reality. A Treatise in the Sociology of Knowledge, New York, Anchor/Doubleday.

BOURGUIGNON C., 2002. Le sol, la terre et les champs, Paris, Sang de la Terre.

BRUNHES DELAMARRE M. J., HAUDRICOURT A. G., [1955] 1986. L'homme et la charrue à travers le monde, Lyon, La Manufacture.

CALLON M., 1986. Some elements of a sociology of translation: domestication of the scallops and the fishermen of St Brieuc Bay. In: Power, Action and Belief: A New Sociology of Knowledge? J. Law, ed. London: Routledge: 196-223.

CALLON M., 1999. Ni intellectuel engagé, ni intellectuel dégagé: la double stratégie de l'attachement et du détachement, Sociologie du travail, 41, 1, pp. 65-78.

CALLON M., MEADEL, C., \& RABEHARISOA, V., 2002. The economy of qualities. Economy and Society, 31, 2, pp. 194-217.

CARADEC V., 2001. Le veuvage, une séparation inachevée, Terrain, 36, pp. 69-84.

CHAPELLE-BARRY C., 2008. Dans le sillon du non-labour, Agreste primeur, 207, http://agreste.agriculture.gouv.fr/IMG/pdf/primeur207.pdf.

CHRISTENSEN C. M., 1997. The innovator's dilemma. When new technologies cause great firms to fail, Boston (MA), Harvard Business School Press.

COUGHENOUR C. M., 2003. Innovating conservation agriculture: the case of no-till cropping, Rural sociology, 68, 2, pp. 278-304.

DUBUISSON-QUELLIER S., LE VELLY R., 2008. Les circuits courts entre alternative et hybridation. dans $\mathrm{G}$. Maréchal (dir.), Les circuits courts alimentaires. Bien manger dans les territoires, Dijon, Éducagri, pp. 105-112.

EKBOIR J. M., 2003. Research and technology policies in innovation systems: zero tillage in 
Revista Tecnologia e Sociedade, Curitiba, v. 11, n. 23, 2015

ISSN (versão online): 1984-3526

ISSN (versão impressa): 1809-0044

Brazil, Research policy, 32, 4, pp. 573-586.

GOMART É., 1999. Surprised by methadone: experiments in substitution, thèse de doctorat de sociologie, Paris, École des Mines.

GOULET F., 2010. Nature et ré-enchantement du monde, dans B. Hervieu, N. Mayer, P. Muller, F. Purseigle, J. Rémy (dirs.), Les mondes agricoles en politique. De la fin des paysans au retour de la question agricole, Paris, Presses de Sciences Po, pp. 51-72.

GOULET F., 2011. Accompagner et vendre. Les firmes de l'agrofourniture dans l'innovation et le conseil en agriculture, Cahiers agricultures, 20, 5, pp. 382-386.

GOULET F., GROSSO S., 2013. Ciencia a demanda. Prácticas alternativas de investigación y extensión en la agronomía de los cultivos extensivos, Pampa, Revista Interuniversitaria de Estudios Territoriales, 9, pp. 129-148.

GOULET F., HERNANDEZ V., 2011. Vers un modèle de développement et d'identités professionnelles agricoles globalisés? Dynamiques d'innovation autour du semis direct en Argentine et en France, Revue tiers monde, 207, pp. 115-132.

HALL A., 1998. Sustainable agriculture and conservation tillage: managing the contradictions, Canadian review of sociology and anthropology, 35, 2, pp. 221-251.

HATCHUEL A., 1998. Comment penser l'action collective? Théorie des mythes rationnels dans R. Damien, A. Tosel (éds.), L'action collective. Coordination, conseil, planification, Besançon, Presses Universitaires de Franche-Comté, pp. 177-202.

HETHERINGTON K., 2004. Secondhandedness: consumption, disposal and absent presence, Environment and planning D: society and space, 22, 1, pp. 157-173.

HUGUES T. P., 1983. Networks of power. Electrification in Western society, 1880-1930, Baltimore (MD), Johns Hopkins University Press.

LABREUCHE J. et al., 2007. Évaluation des impacts environnementaux des Techniques Culturales Sans Labour en France, ADEME-ARVALIS Institut du végétal-INRA-APCAAREAS-ITB-CETIOMIFVV.

LAURENT C., REMY J., 2004. Multifonctionnalité, activités, identités, Les cahiers de la multifonctionnalité, 7 , pp. 5-15.

LEMERY B., 2003. Les agriculteurs dans la fabrique d'une nouvelle agriculture, Sociologie du travail, 45, 1, pp. 9-25.

LOUREAU R., 1970. L’analyse institutionnelle, Paris, Éditions de Minuit.

MAGUIRE S., HARDY C., 2009. Discourse and desinstitutionalization: the decline of DDT, Academy of management journal, 52, 1, pp. 148-178.

MARCH J. G., OLSEN J. P., 1989. Rediscovering institutions. The organizational basis of politics, New York (NY), Free Press.

PINCH T. J., BIJKER W. E., 1984. The social construction of facts and artefacts: or how the sociology of science and the sociology of technology might benefit each other, Social studies of science, 14, 3, pp. 399-441.

ROGERS E. M., 1962. Diffusion of innovations, New York (NY), Free Press of Glencoe. 
Revista Tecnologia e Sociedade, Curitiba, v. 11, n. 23, 2015

ISSN (versão online): 1984-3526

ISSN (versão impressa): 1809-0044

RYAN B., GROSS N. C., 1943. The diffusion of hybrid seed corn in two lowa communities, Rural sociology, 8, 1, pp. 15-24.

SCHUMPETER J A. [1912] 1934. The Theory of Economic Development: An Inquiry into Profits, Capital, Credit, Interest and the Business Cycle (2nd ed.). Cambridge: Harvard University Press.

SUDDABY R., GREENWOOD R., 2005. Rhetorical strategies of legitimacy. Administrative science quarterly, 50, 1, pp. 35-67.

THIEBAULT L., 1994. Sol, agriculture et environnement: une rencontre à ménager. Natures, sciences, sociétés, 2, 2, pp. 129-142.

VON HIPPEL E., 1976. The dominant role of users in the scientific instrument innovation process. Research policy, 5, 3, pp. 212-239.

WHITE H. C., 1992. Identity and control. A structural theory of action. Princeton (NJ), Princeton University Press. 